Original

\title{
Effects of simvastatin on bone regeneration in the mandibles of ovariectomized rats and on blood cholesterol levels
}

\author{
Juliana C. Junqueira, Maria N. G. Mancini, Yasmin R. Carvalho, \\ Ana Lia Anbinder, Ivan Balducci and Rosilene F. Rocha \\ Department of Bioscience and Buccal Diagnosis, \\ São José dos Campos School of Dentistry, UNESP, \\ São Paulo, Brazil
}

(Received 22 January and accepted 20 August 2002)

\begin{abstract}
The purpose of this study was to evaluate the effects of simvastatin on guided bone regeneration in the mandibles of ovariectomized rats, and to observe their blood cholesterol levels. Seventy female rats were divided into two groups: control and treated, both groups containing normal and ovariectomized rats. A month after ovariectomy a bone defect was created in the mandible, and was covered by a polytetrafluoroethylene membrane. The treated groups received simvastatin orally for 15 or 30 days. The rats were sacrificed 15,30 or 60 days after surgery, at which time a blood sample was extracted for blood cholesterol level analysis and the mandible was extracted for densitometric, histological and morphometric analysis. All specimens underwent analysis of variance. The ovariectomized animals had higher cholesterol levels than the treated normal animals, and no significant difference was found between the different treatment periods and the sacrifice times. The densitometric, histological and morphometric analysis showed that the treated ovariectomized animals developed more new bone than the control ovariectomized rats, but no significant difference was observed between the treatment periods. It can be concluded that the deficiency of estrogen increased the level of blood cholesterol and that the simvastatin aided new bone formation in the ovariectomized animals. (J. Oral Sci. 44, 117-124, 2002)
\end{abstract}

Correspondence to Dr. Juliana Campos Junqueira, Job Aires Dias 121, Centro, CEP 12308-160, Jacareí, São Paulo, Brazil Tel: $12-39535627$

Fax: 12-39212036

E-mail: julianacjunqueira@hotmail.com
Key words: bone regeneration; simvastatin; ovariectomy; cholesterol.

\section{Introduction}

With increasing life expectancy for the human species, osteoporosis has become a crucially important factor in the quality of life of elderly people, and it is now one of the most frequently studied diseases. Much effort has been put into finding new medication that not only reduces bone loss related to age and menopause, but also increases bone mass in people with already established disease. The incidence of osteoporosis is significantly higher in women than in men, due to the reduction in estrogen levels caused by ovarian failure after menopause (1).

Mandibular bone, together with the rest of the skeleton, goes through a continuous process of bone density reduction after the age of 50 (2), and it is very important for dentists to understand the systemic hormonal changes in the oral bone structures. Many studies have been undertaken in humans and in ovariectomized animals to observe the effects of osteoporosis in the mandible (1).

Another field of dental interest is bone defect regeneration following cysts, infections, tumors and other factors. Bone regeneration is a complex process influenced by age, bone structure, vascularization, involvement of soft tissues and size of defect (3).

Bone tissue has an extraordinary capacity to remodel and regenerate, being dependent on the interaction of nutrients, medicines, hormones, and growth factors (4). The statins or inhibitors of 3-hydroxy-3-methylglutaryl coenzyme A reductase (HMG-CoA) are widely used for the treatment of hypercholesterolemia. Many kinds of statins 
can be found today including lovastatin, simvastatin, pravastatin, fluvastatin, atorvastatin and cerivastatin (5). Recent studies have shown that these medicines are also capable of increasing bone formation in cell culture and experimental animals, and might be useful in osteoporosis treatment (6).

Mundy et al. (6) studied the effects of simvastatin in normal and ovariectomized female rats. Simvastatin was given in doses of 5 to $50 \mathrm{mg} / \mathrm{kg} /$ day by oral gavage for 35 days. These authors concluded that administration of simvastatin to rats increased the volume of trabecular bone and increased the rate of bone formation, even in ovariectomized animals in which bone loss is accelerated. Therefore, the purpose of our study was to evaluate the effects of simvastatin on guided bone regeneration of mandibular defects of normal and ovariectomized female rats, and to correlate these findings with blood cholesterol levels.

\section{Materials and Methods}

Seventy female rats (Rattus norvegicus, var. albinus, Wistar) were used in this study. The rats were anesthetized during all surgical procedures with Rompun solution (Bayer - São Paulo, SP, Brazil) and Francotar (Virbac - Roseira, $\mathrm{SP}$, Brazil) in the proportion of 1:0.5 mL, $0.1 \mathrm{ml} / 100 \mathrm{~g}$ dose, administered intramuscularly.

Thirty-five animals were ovariectomized after two months. A longitudinal incision in the skin and muscle and ovarian exposure were made. Hemostasis was performed by ligature of the superior part of the tube with a silk thread $n^{\circ} 4$ (Ethicon/ Johnson \& Johnson - São José dos Campos, SP, Brazil). The ovaries, as well as the surrounding fat, the oviduct and a small part of the uterus were excised. The muscular layers were sutured with absorbable suture thread catgut $n^{\circ} 4$ (Cirumédica - Cotia, SP, Brazil) and the skin with silk thread $n^{\circ} 4$ (Ethicon/ Johnson \& Johnson São José dos Campos, SP, Brazil). This procedure was performed bilaterally.

At three months, a bicortical bone defect at the angle of the right mandible was made in all rats. After the skin and the muscle incisions and the dissection of the soft tissues, a bone defect was created with a slow speed and 2.5 and $3.7 \mathrm{~mm}$ diameter burs (Aseptico - Woodinville, WA, USA). The lesion was covered with a polytetrafluoroethylene barrier (Brasflon/ Tecnoflon - São Paulo, SP, Brazil) on both surfaces, vestibular and lingual. The muscular and skin layers were then sutured, respectively, with absorbable suture thread catgut $\mathrm{n}^{\circ} 4$ (Cirumédica - Cotia, SP, Brazil) and silk thread n ${ }^{\circ} 4$ (Ethicon/ Johnson \& Johnson - São José dos Campos, SP, Brazil).

Immediately after the surgery, the animals were divided into two groups: treated, with two subgroups, normal and ovariectomized animals (Table 1) and control, with two subgroups, normal and ovariectomized animals (Table 2). The first group was composed of 40 animals and the second of 30. The treated group received $20 \mathrm{mg} / \mathrm{kg} /$ day of simvastatin (Sinvascor, Baldacci - São Paulo, SP, Brazil) orally for 15 or 30 days. Each subgroup was sacrificed 15, 30 or 60 days after surgery.

When the rats were sacrificed, $2 \mathrm{~mL}$ of blood was taken from the abdominal aorta, and the right mandible was extracted from each rat. Analysis of the total cholesterol level in the plasma samples was performed using the modified Huang method (7), based on the Liebermann-Burchard reaction.

For the optical density analysis, radiographs were taken with occlusal film (Kodak Ektaspeed Plus EO-41P - São José dos Campos, SP, Brazil) and on each film two mandibles and a step wedge were placed (Fig. 1). The opti-

Table 1 Animals treated with simvastatin at different periods of treatment and sacrifice

\begin{tabular}{|c|c|c|c|c|}
\hline \multirow{2}{*}{$\begin{array}{c}\text { Treated } \\
\text { group }\end{array}$} & \multicolumn{2}{|c|}{15 day treatment } & \multicolumn{2}{c|}{30 day treatment } \\
\cline { 2 - 5 } & $\mathrm{S}=15$ days & $\mathrm{S}=30$ days & $\mathrm{S}=30$ days & $\mathrm{S}=60$ days \\
\hline normal & $5^{*}$ & 5 & 5 & 5 \\
ovariectomized & 5 & 5 & 5 & 5 \\
\hline
\end{tabular}

*number of animals in subgroup S: sacrifice

Table 2 Control animals at different periods of treatment and sacrifice

\begin{tabular}{|c|c|c|c|}
\hline Control group & $\mathrm{S}=15$ days & $\mathrm{S}=30$ days & $\mathrm{S}=60$ days \\
\hline normal & $5^{*}$ & 5 & 5 \\
ovariectomized & 5 & 5 & 5 \\
\hline
\end{tabular}

*number of animals in subgroup

S: sacrifice 
cal density of the radiographs was measured using a photodensitometer (M.R.A. - Ribeirão Preto, SP, Brazil), with an aperture size of $1 \mathrm{~mm}$. Readings were taken for the center of the bone defects and of the step wedge for each radiograph. An equivalent aluminum thickness value was then found for each bone defect, through a linear regression model (8) structured with the values of the optical density of the eight steps of the step wedge and its respective aluminum thickness.

After the radiographs were taken, the mandibles were decalcified in a 20\% formic acid aqueous solution (Merck - Darmstadt, Germany). They were then analyzed with a loupe and hemisectioned at the central region of the bone defect, in an anteroposterior direction. The fragments were mounted in paraffin, parallel to the sectioned surface, and four serial sections approximately $5 \mu \mathrm{m}$ thick were obtained, and stained by the hematoxylin-eosin method.

The histomorphometrical analysis was made using a stereological method based on the one proposed by Taga and Stipp (9). The volume density evaluation ( $V v i)$ was expressed in percentages, using a square reticule and the

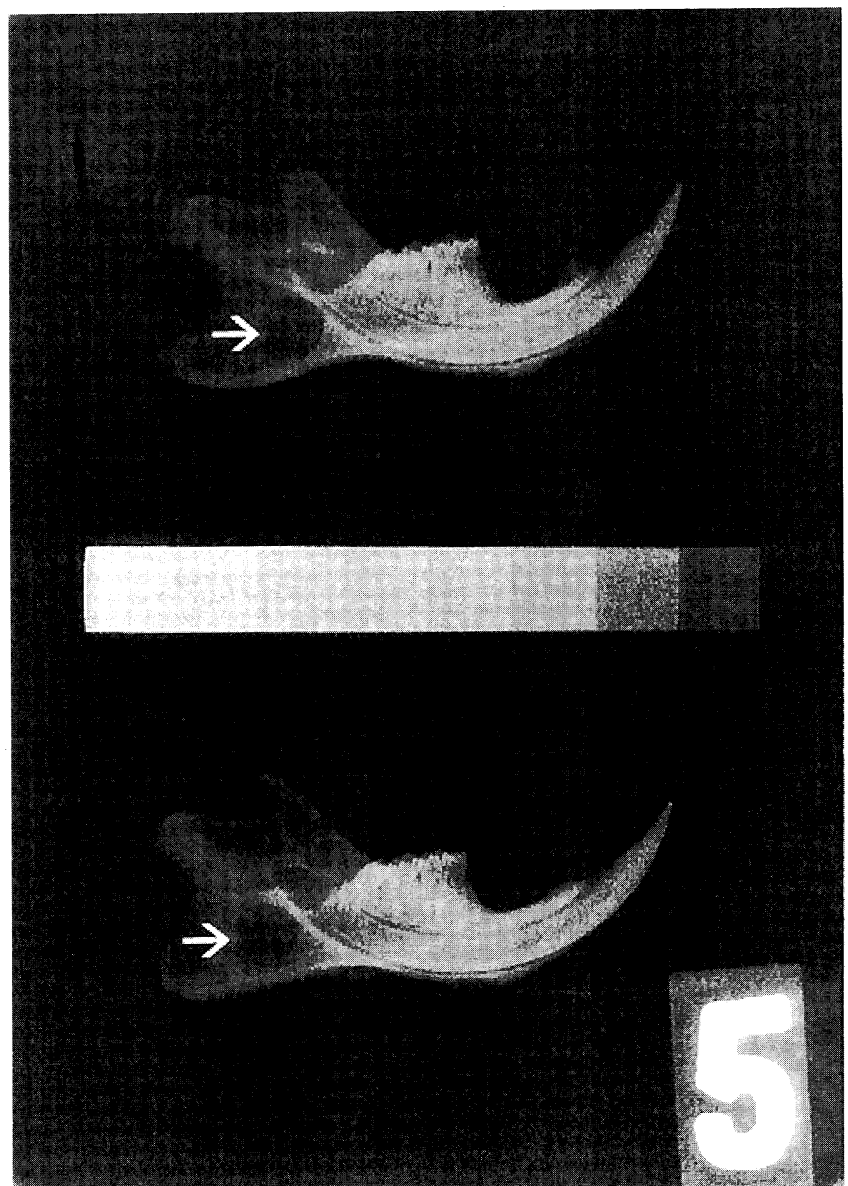

Fig. 1 Radiograph of two mandibles containing bone defects $(\rightarrow)$, an aluminum step wedge with eight steps and an identification number. $\mathrm{x} 20$ objective. The image of the reticule was laid over the histological field, and a count was made of the number of intersection points between the lines of reticule, which overlapped a determined studied structure $(P i)$ and the total number of points over the bone defect $(P)$. The fraction of the volume density of the bone defect occupied by this structure was calculated using the formula below (9).

$$
\mathrm{Vvi}=\frac{\text { number of points over the structure }(P i)}{\text { total number of points over the bone } \operatorname{defect}(P)} .
$$

The histological variations considered for the quantification $(P i)$ were bone tissue structures such as bone matrix, osteocyte lacunas, osteoblasts and osteoclasts.

The results of the cholesterol levels, optic densitometry and histomorphometry were subjected to analysis of variance (ANOVA) and the Tukey's test at a significance level of $5 \%$.

\section{Results}

The mean blood cholesterol level was higher in the ovariectomized rats, and statistical analysis showed that the blood cholesterol levels in the normal treated animals were significantly lower than in the ovariectomized rats, both in the control and treated groups (Fig. 2). Moreover, no significant difference was found between the control and treated groups of the normal animals, nor between the control and treated groups of the ovariectomized animals, indicating that the simvastatin did not exert a hypolipidemic effect. Furthermore, no statistically significant difference was observed in relation to the different times of treatment and period of sacrifice.

The statistical analysis of the optical density using aluminum equivalents revealed that the ovariectomized ani-

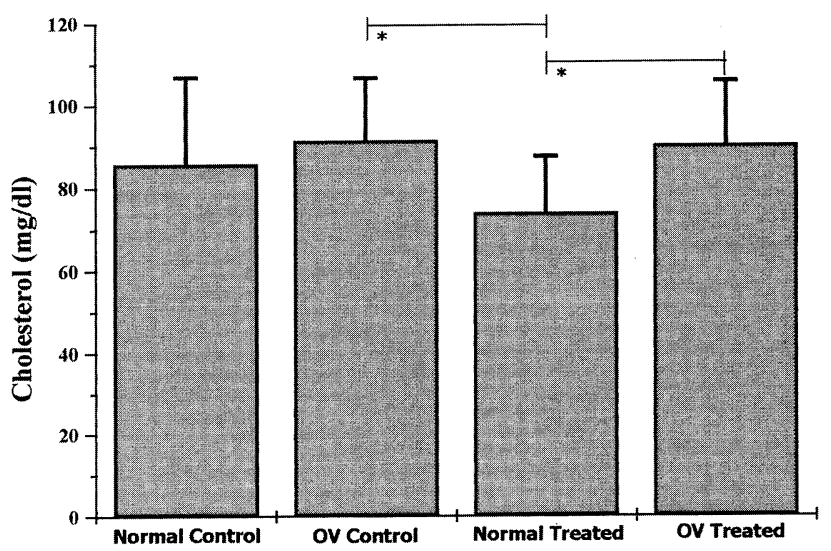

Fig. 2 Graphs of means and standard deviation of the blood cholesterol levels of studied groups. OV = ovariectomized. Statistically significant difference between: normal treated and OV control; normal treated and OV treated $(* P<0.05)$ 
mals had higher mean values than the other animals (Fig. 3 ). The rats killed on day 60 had higher mean values than those killed on day 15 and on day 30 . However, there was no statistically significant difference between the studied groups for the period of treatment.

Histological analysis of the animals sacrificed on day 15 showed that the bone defect was filled with granulation tissue with many cells and vessels. The margins of the lesion contained osteogenic tissue and some immature trabecular bone surrounded by osteoblasts, many voluminous osteocytes and some osteoclasts. These trabeculae surrounded wide marrow spaces, filled with connective tissue. On the surface of the mandibular bone, adjacent to the lesion, newly-formed subperiosteal bone, which showed continuity with the trabeculae formed inside the

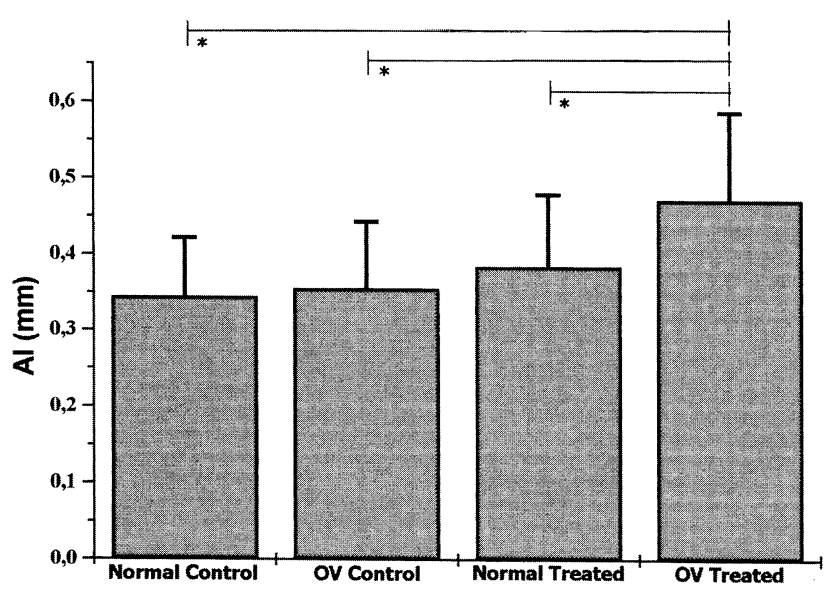

Fig. 3 Graphs of means and standard deviation of optical density in aluminum equivalent for studied groups. OV $=$ ovariectomized. Statistically significant difference between: OV treated and normal control, OV control, normal treated $(* P<0.05)$.

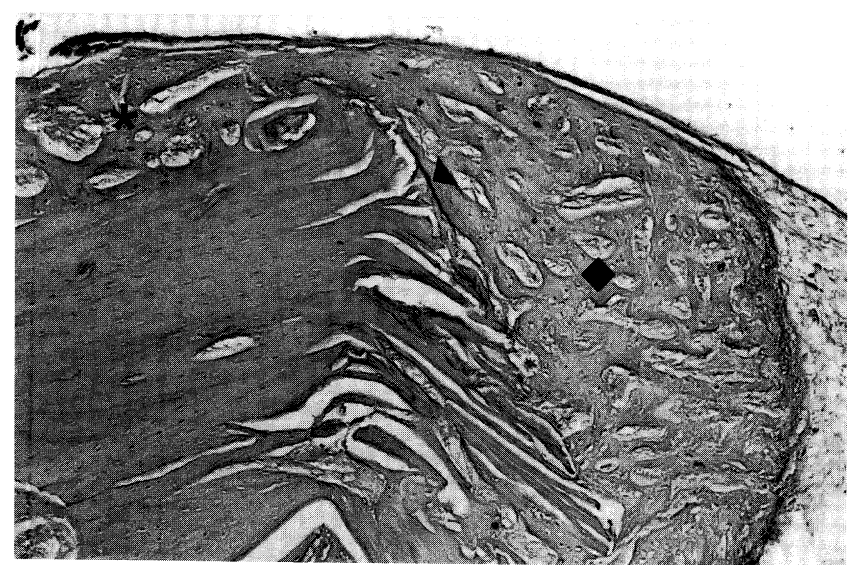

Fig. 415 day period, ovariectomized control group: immature trabecular bone $(\checkmark)$ near the margin of the defect $(\boldsymbol{\nabla})$ and subperiosteal newly-formed bone $(\star)$. Magnification $100 \times$. defect, was observed (Figs. 4 and 5).

The extremities of the bone defects of the animals killed after 30 days exhibited more mature newly-formed bone trabeculae, which extended into the center of the lesion (Fig. 6). Numerous smaller osteocytes were observed in these trabeculae, sometimes disposed in a lamellar pattern, and with marrow spaces of various sizes containing connective tissue or hematopoietic marrow tissue (Fig. 7). The central area of the defect was filled with connective tissue.

The bone defects of the animals killed after 60 days were filled with a lot of newly-formed bone tissue, except in the central area, where connective tissue remained (Fig. 8). The bone trabeculae were mature, with small osteocytes arranged in a lamellar pattern. Appositional lines and small marrow spaces with hematopoietic tissue were also observed (Fig. 9). In the posterior extremity of the defect it was not possible to determine the limit between the old

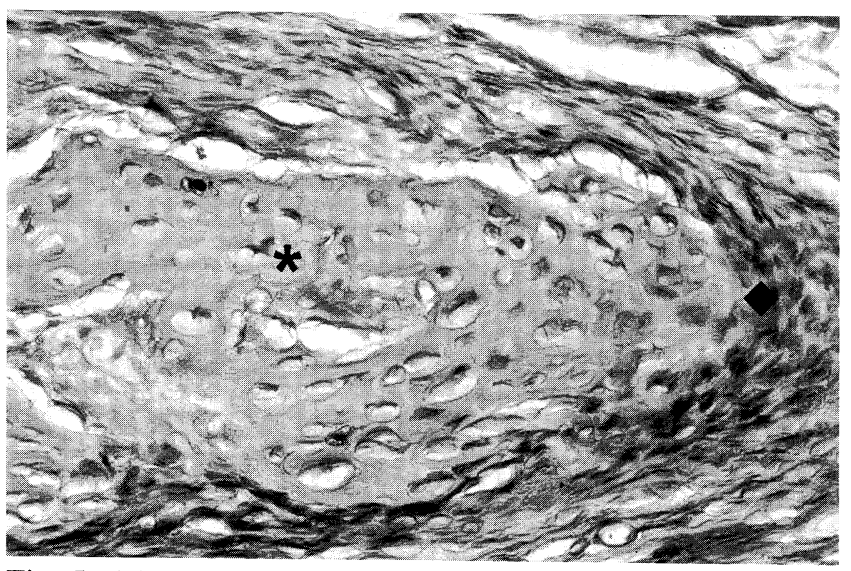

Fig. 515 day period, normal control group: newly-formed bone tissue $(\boldsymbol{\star})$ surrounded by osteogenic tissue $(\boldsymbol{\bullet})$. Magnification $400 \times$.

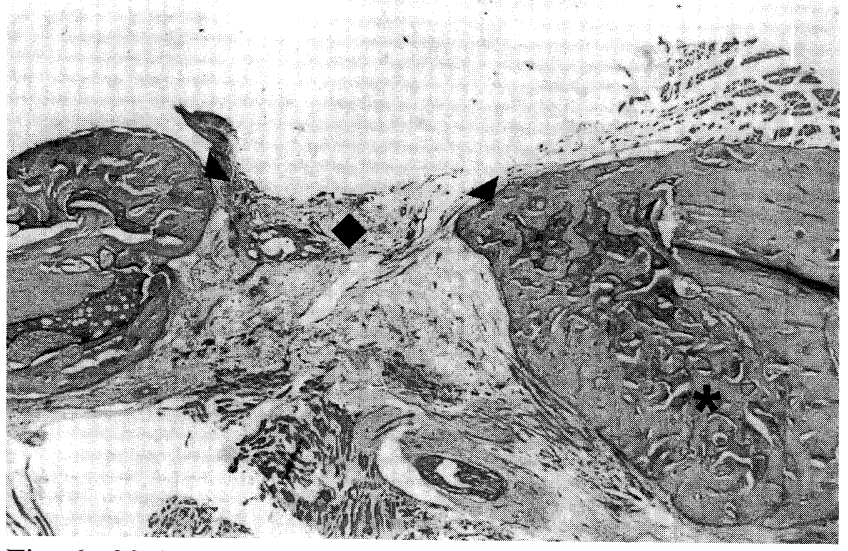

Fig. 630 day period, ovariectomized treated group: lesion presenting connective tissue in the central region $(\diamond)$ and in the margins bone trabeculae $(\boldsymbol{\nabla})$, originating from subperiosteal neoformation (*). Magnification $25 \times$. 
and the newly formed bone.

It was also observed in the histological analysis that the ovariectomized treated animals exhibited more newly formed bone tissue inside the defect in comparison to the ovariectomized control animals sacrificed on days 15, 30, and 60. Moreover, the bone regeneration of the ovariectomized control rats was inferior to that of the normal control rats, sacrificed on days 30 and 60 .

Statistical analysis of the histomorphometry showed that in the control group, the ovariectomized animals had lower mean values in comparison to the normal animals, in the 30 and 60 day periods. Significant statistical differences were observed between the ovariectomized animals of the control and treated groups, proving that treatment with simvastatin improved the bone regeneration of the ovariectomized rats (Fig. 10). The most newly formed bone tissue was found in the defects of animals killed after 60 days, followed by those killed after 30 and 15 days.

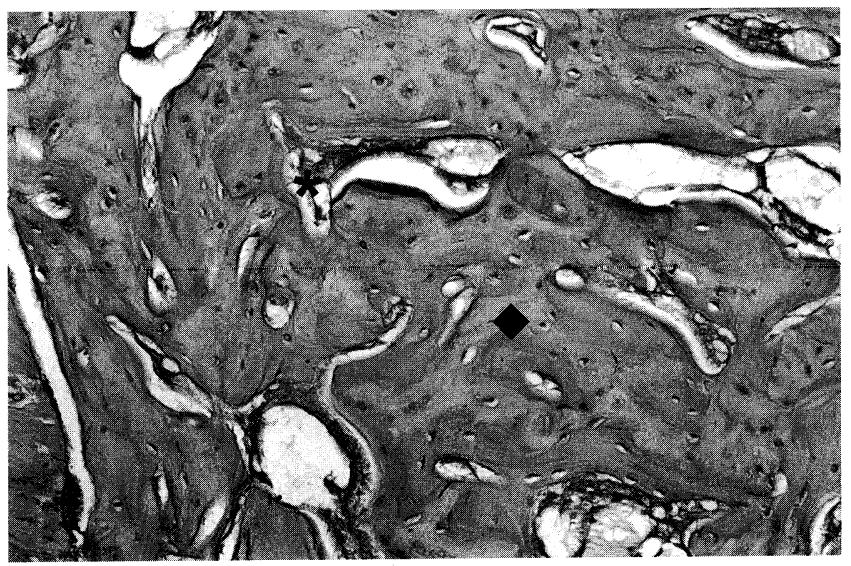

Fig. 730 day period, normal treated group: thick bone trabeculae $(\diamond)$, containing many marrow spaces filled with connective tissue $(\boldsymbol{\star})$. Magnification $200 \times$.

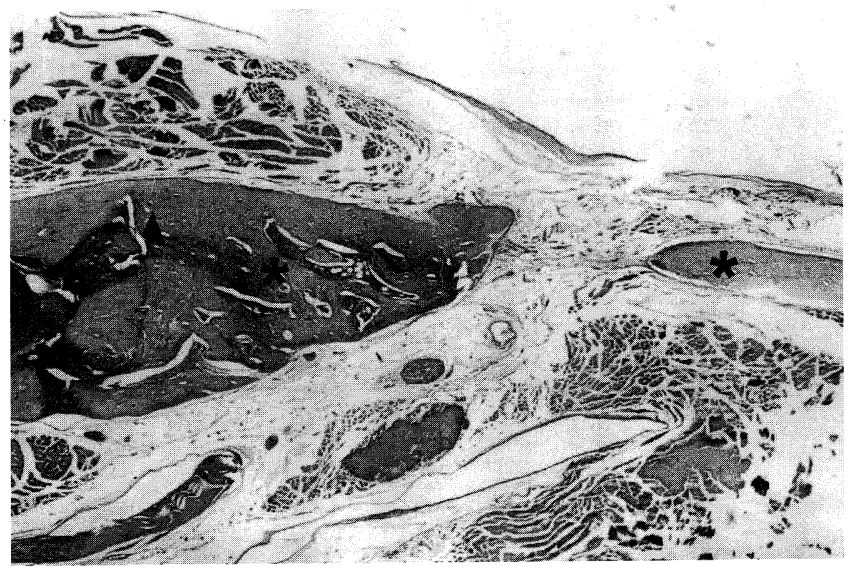

Fig. 860 day period, normal control group: newly-formed bone $(\boldsymbol{*})$ which extends to the margin of the defect $(\boldsymbol{\nabla})$ into the central portion of it. Magnification $25 \times$.
However, no difference was observed between the periods of treatment.

\section{Discussion}

The results of the cholesterol tests showed that the ovariectomized animals had higher blood cholesterol levels than the normal animals. These data agree with many studies that have report an increase in LDL cholesterol in women after menopause $(10,11)$ and hypercholesterolemia in ovariectomized rats (12-14).

It was also observed that treatment with simvastatin did not exert a hypolipidemic effect, in either normal or ovariectomized rats. These data agree with other studies, which demonstrate the ineffectiveness of statins in reducing blood cholesterol levels in rats and hamsters (15-19).

The administration of statins in humans, rabbits and dogs

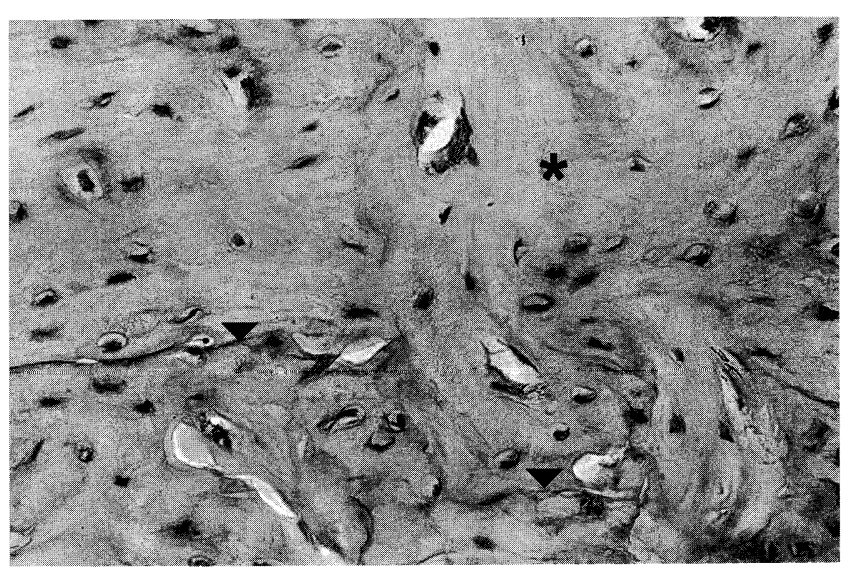

Fig. 960 day period, normal control group: mature newlyformed bone tissue $(\boldsymbol{*})$ containing some appositional lines $(\boldsymbol{\nabla})$. Magnification $400 \times$.

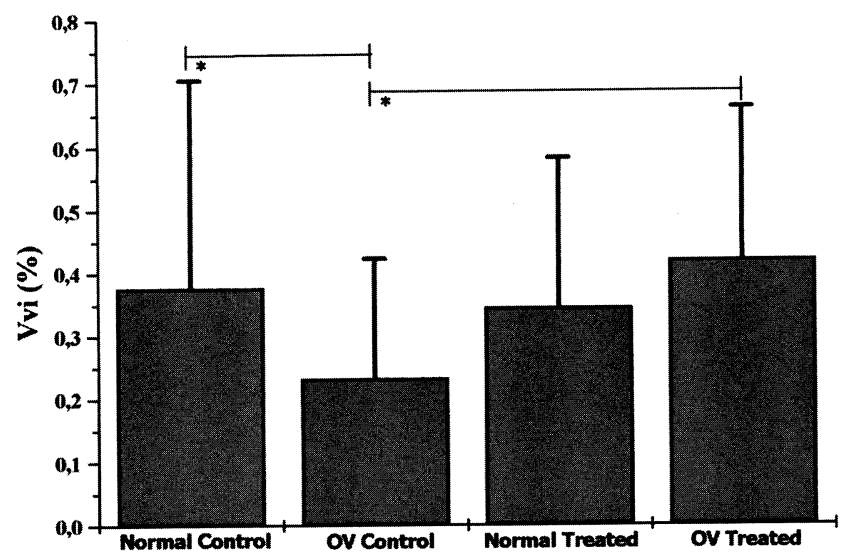

Fig. 10 Graphs of means and standard deviation of the analysis of bone volume density (Vvi) of the studied groups. $\mathrm{OV}=$ ovariectomized. Statistically significant difference between: normal control and OV control; OV control and $\mathrm{OV}$ treated $(* P<0.05)$. 
inhibits the HMG-CoA enzyme reductase, causing a compensatory increase in the quantity of these enzymes. This effect stimulates the surface of hepatocytes to express LDL receptors, which are responsible for the extraction of these lipoproteins from the plasma. In rats, a compensatory increase in HMG-CoA reductase after the use of statins has also been observed. However, this effect is not followed by an increase in LDL receptors. This mechanism cannot be explained yet, but it has been suggested that the inhibition of HMG-CoA enzyme reductase in rats leads to a degradation of LDL receptors (17).

Photographic or optical density analysis is the measurement of the film image through a photodensitometer, which compares the light intensity that enters a determined area in one side of the developed film with the intensity of the same light when it emerges from the other side. Therefore, the value of the optical density depends on the appearance of the radiograph, which is affected by changes during exposure and processing. In our study, the optical density values were transformed into aluminum equivalents, making the method reproducible, independent of the factors of exposure and film processing, and making it possible to compare the optical densities of different radiographs $(20,21)$.

Some studies have attempted to establish a correlation between optical density readings and histological analysis. For example, Bodner et al. (22) studied the regeneration of the alveolus after tooth extraction in rats and Louzada et al. (23) studied the filling of bone defects in the rabbit ulna. These authors noticed a similarity between the results of the densitometric and histological analyses, suggesting that optical densitometry is an efficient method for the evaluation of bone regeneration.

The densitometry performed in this work agreed with only some of the histomorphometric results. The densitometric and histomorphometric analysis both showed that the bone regeneration process for the ovariectomized animals was better for the treated group and for the 60 day observation period. However, histomorphometry was able to point out other findings, such as the reduced quantity of newly-formed bone in the ovariectomized control animals in comparison to the normal control animals, and the enhanced bone regeneration for the 30 day period when compared to the 15 day period.

Histological analysis of every group showed that bone regeneration is initiated at the margins of the defect and from the periosteum. These findings confirm those of other authors, that the periosteum has great osteogenic potential, and is crucial for the regeneration process $(24,25)$.

Osteoclasts were found in the three periods of observation, especially in the animals killed at 15 days, and appo- sition lines were also observed after 30 and 60 days. These data indicate that during the process of bone regeneration, remodeling of the primary bone occurs, forming a more mature tissue, with smaller osteocytes arranged in a lamellar pattern $(26,27)$. The bone tissue regenerates its original structure completely $(28,29)$, and in some histological sections after 60 days, it was impossible to differentiate the posterior margin of the defect due to the similarity between the old and newly formed bone.

The histomorphometric analysis revealed that in the control group the ovariectomized animals achieved inferior bone regeneration than the normal rats, after 30 and 60 days. In many studies, ovariectomization of experimental animals has been associated with deficiencies in the bone regeneration process $(30,31)$.

Through the histomorphometric analysis it was also observed that simvastatin enhanced the bone regeneration in ovariectomized rats. However, in the normal rats, there were no effects on the regeneration process.

The effect of simvastatin on the mandibular bone defect in ovariectomized rats is probably associated with the increase in bone density caused by the use of this medicament for osteoporosis. Wang et al. (32) verified, while studying the femur of rabbits with osteoporosis induced by steroids, that animals treated with steroids and lovastatin for 13 weeks achieved higher bone density than the group treated only with steroids. Mundy et al. (6) also noticed an increase in the volume of trabecular bone in ovariectomized rats treated with simvastatin.

The main mechanism of action of the statins is to increase bone formation through stimulation of bone morphogenetic protein (BMP), which is important in the differentiation and induction of osteoblasts $(6,33)$. Sugiyama et al. (33) proved that the effect of simvastatin on BMP-2 is the result of inhibition of HMG-CoA reductase and that this enzyme is a regulator of bone morphogenetic protein expression. Moreover, the statins inhibit the bone reabsorption process because they induce osteoclast apoptosis by the same mechanism as biphosphonates containing nitrogen (34).

Although the exact mechanism by which the statins act on the bone tissue has not been determined, we conclude that simvastatin enhances guided bone regeneration in the mandibles of ovariectomized rats and maintains normal blood cholesterol levels.

\section{Acknowledgments}

This work was supported by FAPESP - Brazil, grant $\mathrm{n}^{\circ}$ 00/03437-0.

The authors would like to thank Baldacci S. A. Laboratory - Brazil for donating the medication Sinvascor and 
the Dentistry School of Piracicaba - UNICAMP - Brazil for the use of the Radiological Laboratory equipment.

\section{References}

1. Tanaka M, Ejiri S, Kohno S, Ozawa H (1998) The effect of aging and ovariectomy on mandibular condyle in rats. J Prosthet Dent 79, 685-690

2. von Wowern N (1988) Bone mineral content of mandibles: normal reference values-rate of agerelated bone loss. Calcif Tissue Int 43, 193-198

3. Dahlin C, Sandberg E, Alberius P, Linde A (1994) Restoration of mandibular nonunion bone defects. An experimental study in rats using an osteopromotive membrane method. Int J Oral Maxillofac Surg 23, 237-242

4. Elorriaga M, Lecanda F, Mart_nez JA, Larralde J (1995) Changes in skeletal metabolism after the administration of demineralized bone proteins and fluoride. Rev Esp Fisiol 51, 163-164

5. Bellosta S, Ferri N, Bernini F, Paoletti R, Corsini A (2000) Non-lipid-related effects of statins. Ann Med 32, 164-176

6. Mundy G, Garrett R, Harris S, Chan J, Chen D, Rossini G, Boyce B, Zhao M, Gutierrez G (1999) Stimulation of bone formation in vitro and in rodents by statins. Science 286, 1946-1949

7. Moura RA, Wada CS, Purchio A, Almeida TV (1998) Laboratory technique. 3rd ed, Atheneu, São Paulo, 35-96 (in Portuguese)

8. Kolbeck S, Bail H, Weiler A, Windhagen H, Haas N, Raschke M (1999) Digital radiography. A predictor of regenerate bone stiffness in distraction osteogenesis. Clin Orthop 366, 221-228

9. Taga R, Stipp ACM (1994) Morfometry practical manual of the optical microscopy. Planning and developing an experiment. Bauru School of dentistry, Bauru, 1-35 (in Portuguese)

10. Sonmez AS, Birincioglu M, Turkoz Y, Adam B, Lurie D, Chuong CJ (1999) Effects of misoprostol on lipoprotein (a) levels of ovariectomized rats. Fertil Steril 72, 518-521

11. Tsang TS, Barnes ME, Gersh BJ, Hayes SN (2000) Risks of coronary heart disease in women: current understanding and evolving concepts. Mayo Clinic Proceed 75, 1289-1303

12. Sohn E, Daggy BP, Arjmand BH (1999) Ovariectomized hamster: a potencial model of postmenopausal hypercholesterolemia. J Nut Biochem $10,660-663$

13. Lucas EA, Juma S, Stoecker BJ, Arjmandi BH (2000) Prune suppresses ovariectomy-induced hyper- cholesterolemia in rats. J Nutr Biochem 11, 255-259

14. Kishida T, Ebihara K (2000) Ovarian hormone deficiency-induced hypercholesterolemia is reversed by taurine. Nutr Res 20,1173-1182

15. Endo A, Tsujita Y, Kuroda M, Tanzawa K (1979) Effects of ML-236B on cholesterol metabolism in mice and rats: lack of hypocholesterolemic activity in normal animals. Biochim Biophys Acta 575, 266-276

16. Sakono M, Ibi T, Nagao K, Ikeda I, Yamamoto K, Imaizumi K (1996) Lymphatic transport of cholesterol in normocholesterolemic rats treated with pravastatin, an inhibitor of HMG-CoA reductase. Atherosclerosis 124, 95-102

17. Fujioka T, Tsujita Y (1997) Effects of single administration of pravastatin sodium on hepatic cholesterol metabolism in rats. Eur J Pharmacol 323, 223228

18. Lundeen SG, Carver JM, McKean ML, Winneker RC (1997) Characterization of the ovariectomized rat model for the evaluation of estrogen effects on plasma cholesterol levels. Endocrinology 138, 15521558

19. Hajri $T$, Chanussot $F$, Fèrèzou J, Riottot $M$, Lafont H, Laruelle C, Lutton C (1997) Reduced cholesterol absorption in hamsters by crilvastatin, a new 3hydroxy-3-methylglutaryl coenzyme A reductase inhibitor. Eur J Pharmacol 320, 65-71

20. Trouerbach WT, Steen WHA, Zwamborn AW, Schouten HJA (1984) A study of the radiographic aluminium equivalent values of the mandible. Oral Surg Oral Med Oral Pathol 58, 610-616

21. Verhoeven JW, Ruijter JM, Cune MS, Putter C (1998) Densitometric measurements of the mandible: accuracy and validity of intraoral versus extraoral radiographical techniques in an in vitro study. Clin Oral Implants Res 9, 333-342

22. Bodner L, Kaffe I, Littner MM, Cohen J (1993) Extraction site healing in rats. A radiologic densitometric study. Oral Surg Oral Med Oral Pathol 75, 367-372

23. Louzada MJQ, Paulin JBP, Xavier CAM, Valeri V (1989) Radiografic microdensitometry of bone perforation. Rev Bras Orthop 24, 165-168 (in Portuguese)

24. Eyre-Brook AL (1984) The periosteum: its function reassessed. Clin Orthop 189, 300-307

25. Kostopoulos L, Karring T (1995) Role of periosteum in the formation of jaw bone. An experiment in the rat. J Clin Periodontol 22, 247-254

26. Sandberg MM, Aro HT, Vuorio EI (1993) Gene 
expression during bone repair. Clin Orthop 289, 292-312

27. Vortkamp A, Pathi S, Peretti GM, Caruso EM, Zaleske DJ, Tabin CJ (1998) Recapitulation of signals regulating embryonic bone formation during postnatal growth and in fracture repair. Mech Dev $71,65-76$

28. Meghji S (1992) Bone remodeling. Br Dent J 172, 235-242

29. Hill PA (1998) Bone remodeling. Br J Orthod 25, 101-107

30. Walsh WR, Sherman P, Howlett CR, Sonnabend DH, Ehrlich MG (1997) Fracture healing in a rat osteopenia model. Clin Orthop 342, 218-227

31. Kubo T, Shiga T, Hashimoto J, Yoshioka M, Honjo H, Urabe M, Kitajima I, Semba I, Hirasawa Y (1999) Osteoporosis influences the late period of fracture healing in a rat model prepared by ovariectomy and low calcium diet. J Steroid Biochem Mol Biol 68, 197-202

32. Wang GJ, Chung KC, Shen WJ (1995) Lipid clearing agents in steroid-induced osteoporosis. J Formos Med Assoc 94, 589-592

33. Sugiyama M, Kodama T, Konishi K, Abe K, Asami S, Oikawa S (2000) Compactin and simvastatin, but not pravastatin, induce bone morphogenetic protein-2 in human osteosarcoma cells. Biochem Biophs Res Commun 271, 688-692

34. Luckman SP, Hughes DE, Coxon FP, Graham R, Russel G, Rogers MJ (1998) Nitrogen-containing biphosphonates inhibit the mevalonate pathway and prevent post-translational prenylation of GTP-binding proteins, including Ras. J Bone Miner Res 13, $581-589$ 